\title{
Menkes X linked disease: heterozygous phenotype in uncloned fibroblast cultures
}

\author{
NINA HORN \\ From the Department of Medical Genetics, The John F Kennedy Institute, Glostrup, Denmark
}

SUMmARY The ${ }^{64} \mathrm{Cu}$ incorporation into uncloned fibroblast cultures from 16 Menkes disease mothers and 19 first and second degree female relatives was examined.

The mean incorporation for the Menkes disease mothers $(36 \cdot 2 \pm 3 \cdot 6 \mathrm{SEM})$ differed significantly from that of 25 normal subjects $(21 \cdot 7 \pm 0.9$ SEM) suggesting the presence of a significant proportion of mutant cells. In addition, the results suggested a heterozygous state in a number of the female relatives.

Uncloned fibroblast cultures from four Menkes disease heterozygotes showed increasingly abnormal copper uptake values after repeated freezing procedures. Manipulation of tissue cultures may help to identify a number of female carriers.

Menkes steely hair syndrome is an $\mathrm{X}$ linked recessive disorder of copper metabolism. The clinical picture includes specific copper deficiency symptoms, such as defective keratinisation and pigmentation of hair, degenerative changes of the elastic tissue in the aorta and blood vessels, and scorbutic bone changes. ${ }^{12}$ In addition, progressive psychomotor retardation with seizures and temperature instability results in early death.

At the cellular level the disturbance of the copper metabolism results in accumulation of the metal in several cell types ${ }^{3-5}$ including cells cultured in vitro. $^{6-8}$ Affected males can be diagnosed by increased uptake of labelled copper in cultured fibroblasts and amniotic fluid cells. ${ }^{910}$

According to the Lyon hypothesis, female heterozygotes would be expected to possess both normal and mutant cells. ${ }^{11}$ In a previous paper a mosaic pattern was demonstrated after cloning in cell cultures. ${ }^{12}$ Two distinct cell populations were observed, one in which the normal allele was expressed and one in which the mutant gene could be seen, establishing that the Menkes disease locus is subject to random $\mathbf{X}$ inactivation.

Cloning is, however, a difficult and tedious technique and the possibility of prenatal diagnosis with selective abortion of affected males ${ }^{10}$ has increased the need for a more simple and rapid test for detection of female carriers.

The present study was undertaken in order to Received for publication 19 October 1979 define the characteristics of copper uptake into uncloned cell cultures from Menkes disease carriers and to determine their usefulness for identification of the carrier state in female relatives of Menkes disease patients.

By implication of the random $\mathbf{X}$ inactivation in carrier females, half of the cells, on average, would express the mutant gene and in the other half the normal allele would be active. However, great individual variation can exist, and the proportion of mutant to normal cells could be expected to follow a normal distribution. As would be expected, uncloned cell cultures would show copper incorporation values ranging from absolutely normal to clearly abnormal, provided that no metabolic cooperation existed between normal and mutant cells. The demonstration of intermediate clonal values and significantly increased incorporation values for uncloned cultures from some carriers suggested that no such co-operation existed. ${ }^{12}$

\section{Materials and methods}

The women tested included six obligate heterozygotes, ten women each of whom had one affected son but no other family history, and 19 first and second degree female relatives.

Fibroblast cultures were established by conventional tissue culture techniques and were routinely maintained either in medium 199 supplemented with $20 \%$ human serum from pregnant women or in 
medium F12 supplemented with $20 \%$ fetal calf serum. Cultures from 17 of the females investigated were established in our own laboratory; the remaining 18 cultures were sent from other laboratories. Cell cultures from 18 Menkes disease patients and 25 normal subjects served as controls.

Tests on metabolic co-operation between normal and mutant cells were performed on mixtures of various proportions of cells from Menkes disease patients and normal males.

Cell cultures were routinely stored in liquid nitrogen. The cells were suspended in supplemented medium containing 10\% DMSO (dimethyl sulphoxide), cooled in a Linde biological freezer at a rate of 1.2 to $1.5^{\circ} \mathrm{C}$ per minute down to $-70^{\circ} \mathrm{C}$, and immersed in liquid $\mathrm{N}_{2}$. Cells were recovered from the repository by rapid thawing in a $37^{\circ} \mathrm{C}$ waterbath, diluted with fresh culturing medium $(1: 10)$, and reincubated at $37^{\circ} \mathrm{C}$.

To test the effect of repeated freezing and thawing, four cultures from known carriers initially showing from absolutely normal to clearly abnormal incorporation values were tested. The first passage after recovery was used for the incorporation test. Aliquots of the cells in question were frozen again for subsequent storage and analysis. Between each test the cells were stored in $\mathrm{N}_{2}$ for at least two weeks.

Copper uptake studies were performed according to the method described previously. ${ }^{912}$ In each test both Menkes and normal cell lines were included.

\section{Results}

The mean 20-hour incorporation of labelled copper into cell lines from subjects of various genotypes are presented in the table.

The incorporation values into Menkes and normal cell lines using F12 medium supplemented with $20 \%$ fetal calf serum were similar to those reported previously. ${ }^{9}$ On the basis of the protein content, the mean copper uptake into Menkes fibroblasts was about three times higher than that of normal controls, and no overlap existed between the two genotypes.

TABLE Mean incorporation values into cell lines of various genotypes

\begin{tabular}{lll}
\hline Genotype & $n$ & $\begin{array}{l}\text { 64 copper uptake } \\
(\text { ng/mg protein } / 20 h) \\
(\text { mean } \pm S E M)\end{array}$ \\
\hline Normal & 25 & $21 \cdot 7 \pm 0 \cdot 9$ \\
Menkes disease & 18 & $73 \cdot 0 \pm 3 \cdot 2$ \\
Menkes disease mothers & 16 & $36 \cdot 2 \pm 3 \cdot 7^{*}$ \\
Female relatives & 19 & $24 \cdot 8 \pm 2 \cdot 1$ \\
\hline
\end{tabular}

${ }^{*} \mathrm{p}<0.01$; Mann-Whitney rank test.

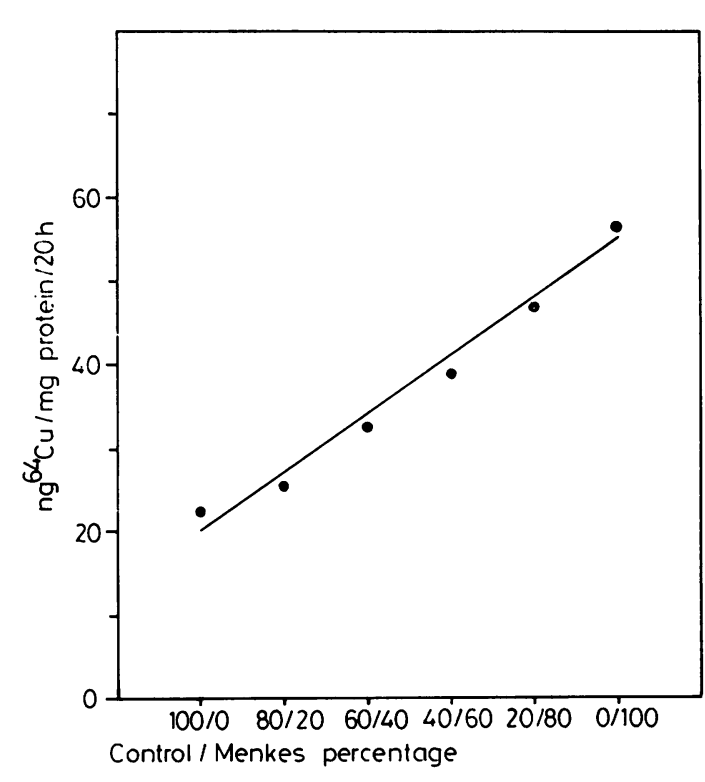

FIG $1{ }^{64} \mathrm{Cu}$ incorporation values in mixtures of control and Menkes cells, showing the cell mixtures indicated as $\%$.

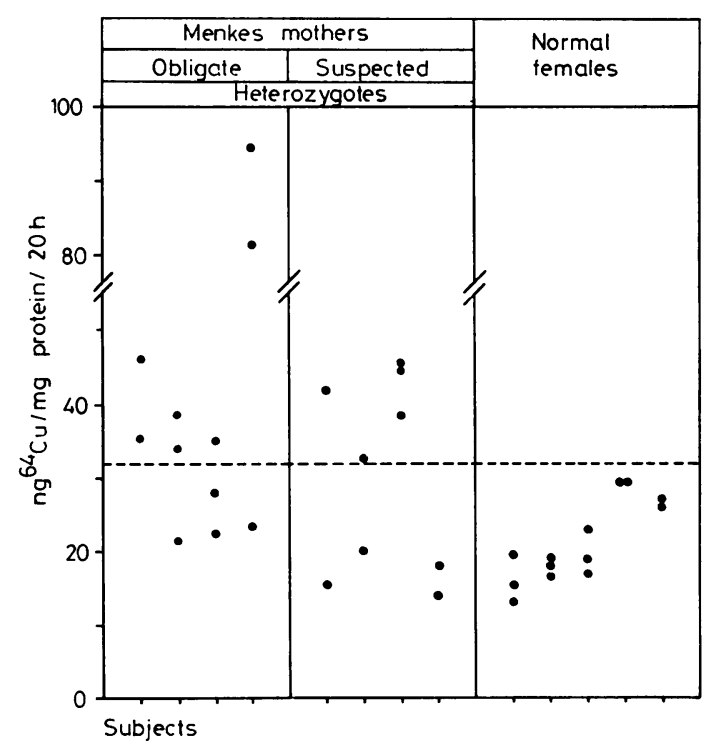

FIG $2{ }^{64} \mathrm{Cu}$ incorporation values into cultures from Menkes disease mothers and normal females. Each dot represents a single culture and cultures from each female are grouped vertically. The horizontal line represents the upper limit of the $95 \%$ confidence limits for the mean value of 25 normal subjects. 
The mean incorporation for 16 Menkes disease mothers differed significantly from that of normal subjects suggesting the presence of a significant proportion of mutant cells. Such a construction was substantiated by co-cultivation of Menkes and normal cell lines demonstrating no metabolic cooperation between cells of the two genotypes. A typical experiment is shown in fig 1 , showing a linear relationship between the incorporation of labelled copper and the proportion of mutant to normal cells.

In eight Menkes disease mothers the variation between two or three independent fibroblast cultures was examined. The results are shown in fig 2 together with the results for cultures from five normal females. The incorporation values into different cultures from each control female showed little variation, whereas for several of the Menkes diseass mothers the values obtained varied considerably. A number of obligate and suspected carrier mothers had incorporation values significantly above the $95 \%$ confidence limit of the normal

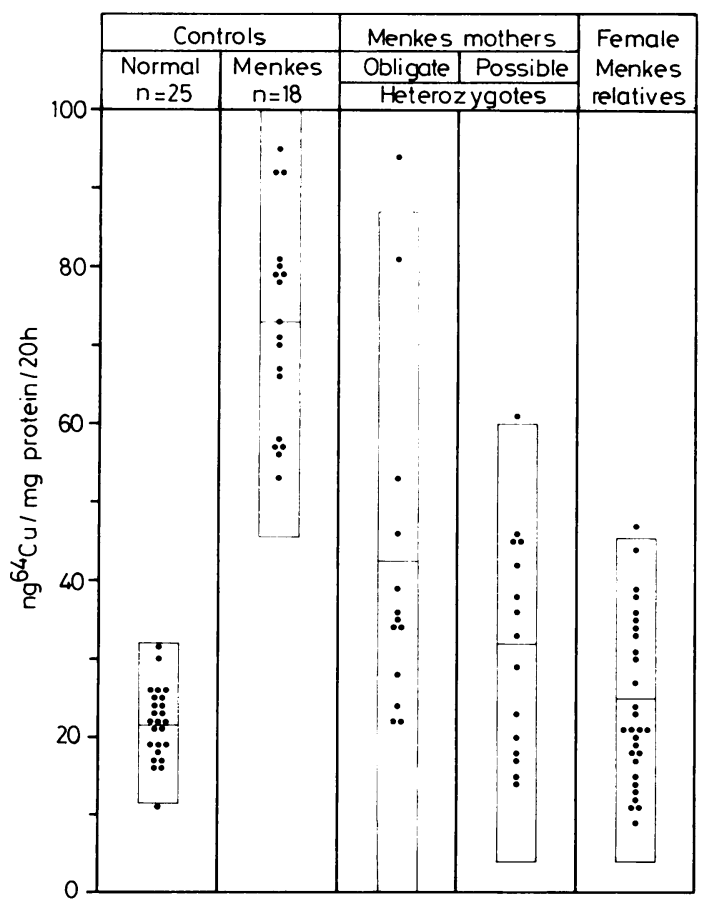

FIG $3{ }^{64} \mathrm{Cu}$ incorporation values in obligate and potential Menkes disease heterozygotes. Each dot represents a single culture except for the controls where each dot represents the mean of all values obtained for the same subject. controls, and one obligate carrier mother had values in the Menkes disease range. As expected, clearly normal incorporation values were also found in each group.

The incorporation values for all the cultures from the females under study are shown in fig 3. Values obtained for cultures from Menkes disease mothers with only one affected son are separated from values obtained for obligate Menkes disease carriers. In the group of female relatives several values were found to be so high that they too should be considered carriers.

The incorporation values for four cultures from known heterozygotes tested after repeated freezing in liquid nitrogen are shown in fig 4. Each culture showed an overall increase in the incorporation values although two were only moderate. Such a systematic change was not observed in normal or Menkes cell lines either after multiple subculturings or after freezing.

The variations of seven normal cell lines tested several times are illustrated in fig 5 together with those obtained for seven Menkes cell lines. Expressed as a percentage of the mean, the variations for the two genotypes are of the same magnitude.

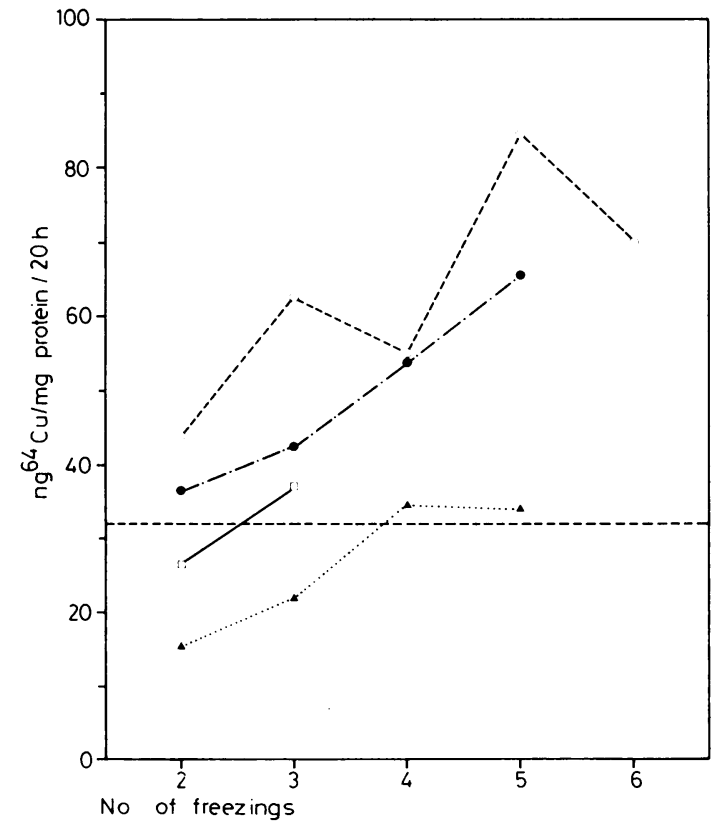

FIG $4{ }^{64} \mathrm{Cu}$ incorporation values for cultures from four Menkes disease heterozygotes after repeated freezing in liquid $N_{2}$. The horizontal line represents the upper limit of the $95 \%$ confidence limits for the mean values of 25 normal subjects. 


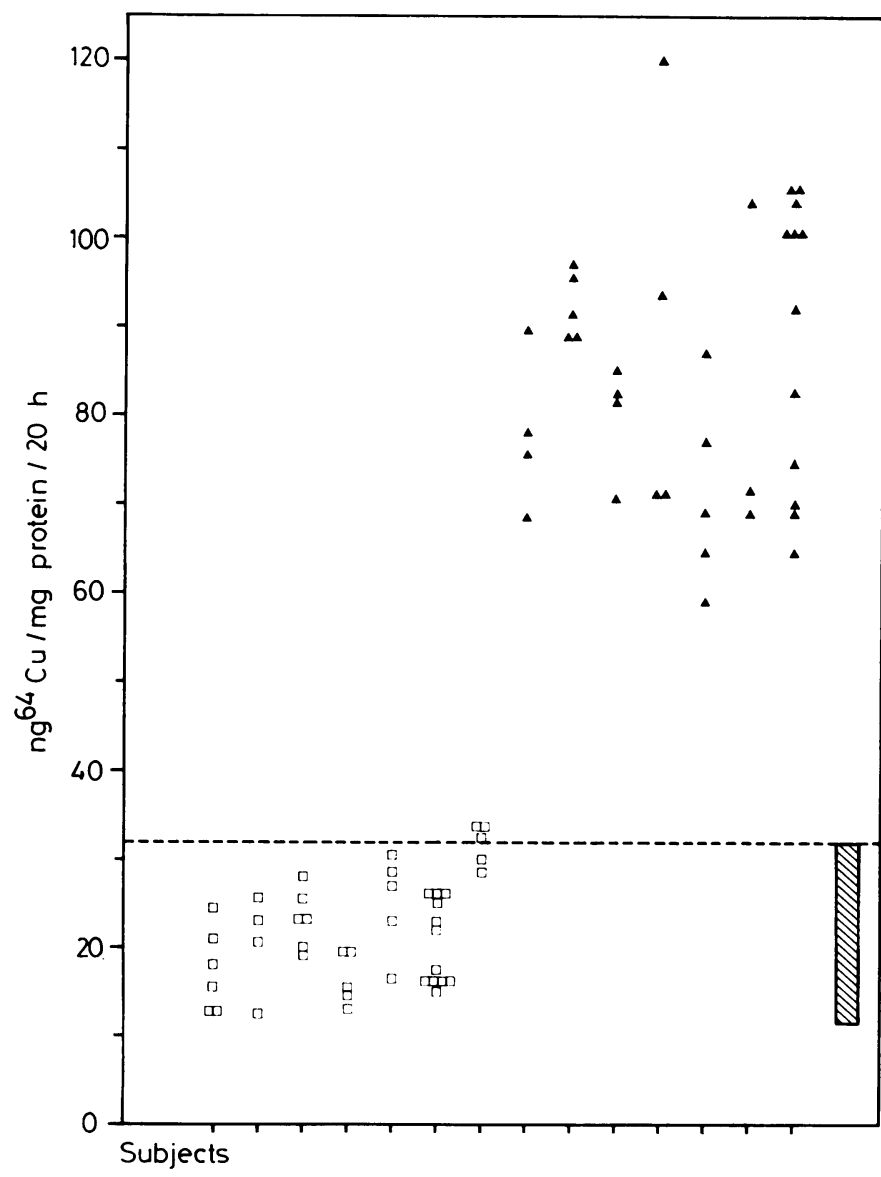

FIG $5{ }^{64} \mathrm{Cu}$ incorporation values for cultures repeatedly tested from normal $\square$ and Menkes disease A subjects. Each symbol represents a single determination on a culture and values from each subject are grouped vertically. The hatched bar represents the normal range as defined by the $95 \%$ confidence limits of the mean of 25 subjects.

\section{Discussion}

The present investigation has established that copper incorporation into uncloned fibroblast cultures can be used for identification of some female heterozygotes for the Menkes gene. However, some carriers with a high proportion of normal cells in the cultures investigated may go undetected by the incorporation test.

In contrast to normal subjects, uncloned cultures from Menkes disease mothers and female relatives showed a wide range of copper incorporation values, from absolutely normal to a clearly abnormal phenotype. These results are compatible with the Lyon hypothesis.

Occasionally, the values obtained from several independent cultures from a single carrier female differed considerably more than could be explained by 'normal variation'. For example, in one obligate carrier, two values in the Menkes disease range and one clearly normal value were obtained. This suggests that for carrier detection more information might be gained by testing a number of cultures rather than a single culture alone.

In the above example the three cultures tested were derived from the same small skin biopsy of approximately $3 \mathrm{~mm}^{2}$, indicating that the proportion of mutant to normal cells may vary considerably even in closely adjacent parts of skin.

From this it is also evident that the mean incorporation results are of limited value in predicting carrier status and may often conceal an otherwise clear cut result. This also applies to repeated tests on the same culture.

In a carrier female, the variation observed between different cultures is influenced by the degree of mosaicism present in each culture and the "normal variation'. This latter variation is, however, impossible to determine by repeated tests, because each intervention may, in theory, cause selection 
of either cell type, and the highest value obtained, therefore, always has to be taken into account for genetic counselling.

Increased incorporation values observed in some uncloned cultures after routine freezing may be an example of selection of the mutant cell type. A similar phenomenon has been reported after prolonged maintenance in culture or routine freezing of uncloned fibroblast cultures from several obligate and potential carriers of another $\mathrm{X}$ linked condition, the Hunter syndrome. ${ }^{13}$ Thus, manipulation of the cell culture, such as routine freezing, may aid in predicting carrier status in some women at risk and this would be of value, especially with borderline normal results.

The technical assistance of Mona Ryberg and Helle Morthorst is gratefully acknowledged. I thank Dr M Mikkelsen for valuable discussions and suggestions on preparation of the manuscript. Colleagues too numerous to be mentioned here are thanked for making patients available for study.

This study was supported by grants from the National Board of Social Welfare and the Danish Medical Research Council.

\section{References}

1 Menkes JH, Alter M, Steigleder GK, Weakley DR, Sung JH. (1962). A sex-linked recessive disorder with retardation of growth, peculiar hair, and focal cerebral and cerebellar degeneration. Pediatrics 1962;29:764-79.

2 Danks DM, Campbell PE, Stevens BJ, Mayne V, Cartwright E. Menkes kinky hair syndrome. An inherited defect in copper absorption with widespread effects. Pediatrics 1972;50:188-201.
3 Heydorn K, Damsgaard E, Horn N, Mikkelsen M, Tygstrup I, Vestermark S, Weber J. Extra-hepatic storage of copper. A male foetus suspected of Menkes disease. Hum Genet 1975;29:171-5.

4 Horn N, Heydorn K, Damsgaard E, Tygstrup I, Vestermark S. Is Menkes syndrome a copper storage disorder? Clin Genet 1978;14:186-7.

5 Horn N, Jensen OA. Menkes syndrome: subcellular distribution of copper by an ultrastructural histochemical technique. Ultrastructural Pathology 1980;1: 237-42.

- Goka TJ, Stevenson RE, Hefferan PM, Howell RE. Menkes disease: a biochemical abnormality in cultured human fibroblasts. Proc Natl Acad Sci USA 1976;73: 604-6.

7 Chan WY, Garnica AD, Rennert OM. Cell culture studies of Menkes kinky hair disease. Clin Chim Acta $1978 ; 88: 495-507$.

8 Beratis NG, Price P, LaBadie G, Hirschorn K. ${ }^{64} \mathrm{Cu}$ metabolism in Menkes and normal cultured skin fibroblasts. Pediatr Res 1978;12:699-702.

- Horn N. Copper incorporation studies on cultured cells for prenatal diagnosis of Menkes disease. Lancet 1976; i: $1156-8$.

10 Horn N, Heydorn K. Prenatal detection of Menkes disease and copper distribution in affected foetuses. Excerpta Medica International Congress Series No 426, 1977:56-7.

11 Lyon MF. X-chromosome inactivation and developmental patterns in mammals. Biol Rev 1972;47:1-35.

12 Horn N, Mooy P, McGuire VM. Menkes X linked disease: two clonal cell populations in heterozygotes. J Med Genet 1980;17:262-6.

13 Booth CW Nadler HL. Demonstration of the heterozygous state in Hunter's syndrome. Pediatrics 1974;53: 396-9.

Requests for reprints to Dr Nina Horn, Department of Medical Genetics, The John F Kennedy Institute, 7 Gl Landevej, DK 2600 Glostrup, Denmark. 